\title{
An Assessment of the Application of Occupational Ergonomics Principles in the Informal Sector of Harare and Mutare in Zimbabwe
}

\author{
Steven Jerie $\mathrm{a}^{*}$ \\ a Midlands State University, Department of Geography and Environmental Studies, Gweru, Zimbabwe. \\ ${ }^{*}$ Corresponding author's email address: sjerie2014@gmail.com
}

\section{A R T I C L E I N F O}

Received: 05-04-2017

Accepted: 06-05-2017

Available online: 25-07-2017

Keywords:

Awareness;

Ergonomics;

Health;

Informal sector;

Occupational hazards;

Safety.

JEL Classification:

D62; J81; M10.

\begin{abstract}
A B S T R A C T
A major challenge for the city authorities of Harare and Mutare in Zimbabwe is to come up with clear policies and actions aimed at supporting and nurturing the informal sector as well as improving health and safety in the sector. This study thus aims at assessing the awareness of ergonomics principles in the small-scale enterprises of Harare and Mutare. The level of awareness of ergonomics principles is low in the small scale informal sectors of Harare and Mutare. It was expected that builders, woodworkers and welders would have a higher level of ergonomic principles, but this was not the case. The informal workers are employed in a high-risk sector, but survey results indicated that improving their work environment is not one of their top priorities. The financial situation and the fact that occupational hazards and diseases are not always visible means that their limited resources are allocated to field other than occupational health and safety. Workers in the informal sector are not affected by the traditional employer-employee relationship as that obtains in the formal sector where the employee is obliged to care for the workers occupational health and safety needs. In order to address occupational health and safety discrepancies in the informal sector there is need for change of mindset and this can be catalysed by the local authorities and other organizations. The local authorities can begin by ensuring basic occupational hygiene skills among the informal sector workers so that they may realize their economic potential and hence sustained businesses.
\end{abstract}

(C) 2017 The Authors. This is an open access article under the terms of the Creative Commons Attribution License 4.0, which allows use, distribution and reproduction in any medium, provided the original work is properly cited.

DOI: http://dx.doi.org/10.18533/rss.v2i6.101

ISSN 2378-8569(Print), ISSN 2378-8550(Online)

\section{Introduction}

Ergonomics studies the complex relationships between people, physical and psychological aspects of the work environment (e.g. facilities, equipment and tools), job demands and work methods (Rongo, 2005). It is that branch of engineering science in which biological science is used to study the relationship between workers and their environments and can thus be regarded as the science of comfort whereby the workplace is fitted to the individual in order to reduce the potential for injury (Miller 2008). The aim of ergonomics is to optimize the comfort, health, safety and efficiency of the worker and in developed countries there are specific ergonomic guidelines for many of the workplaces and this is generally not the case in developing countries that include Zimbabwe and Tanzania.

The economic implosion in Zimbabwe especially after the introduction of the Economic Structural Adjustment in the early 1990s led to the growth of informal sector activities such as food vending, carpentry, metal working, 
mechanics, spray painting and welders among many others. The 1996 Poverty Assessment Survey revealed that $59 \%$ of the population resident in cities was living in poverty. The reduction of expenditure on social services and worse still the removal of subsidies, which were pre-conditions for continued financial support from the International Monetary Fund and the World Bank, pushed the prices of basic commodities beyond the reach of the majority of the people and hence engagement in the informal sector was seen as a viable survival strategy. The decline in real household incomes and retrenchment also led to many people joining the informal sector. Retrenchment in both the private and public sectors resulted in high unemployment rates estimated at $80 \%$ in 2009. The rapid growth in the number of increasingly educated people unable to be absorbed in the formal sector also meant that alternative self employment had to be sought in the informal sector. Over 300000 school leavers are released by the country's education system annually and only 70000 are absorbed by into the formal sector.

Therefore increasing urban poverty, rural-urban migration and declining formal employment opportunities were the major drivers toward informalisation of the Zimbabwean economy (Tevera and Chimhowu, 2000). The ability of the informal sector to provide employment for the ever-increasing number of entrants to the labour labour market is widely acknowledged in literature (Karanja et al., 2003, Atambo, 1995, Nguyen et al., 2010, Sett and Sahu, 2010, Mukhopadhyan, 2008, Chirisa 2009, Nifrik et al., 2003). It is believed that worldwide, half of all workers are engaged in the informal sector (Kayumba and Mlingi, 2003). In Tanzania, 46\% of the working population is active within the informal sector which creates about 3 million jobs. According to the Small, Medium and Micro Enterprises (SMME) Policy of Botswana, approximately 563000 SMME business operate in Botswana, with 125000 people employed (Rogoeng, 2003). Of these businesses, 50000 are micro enterprises and 60000 are small enterprises. In Kenya the informal sector economy employs over 4.2 million people in both the rural and urban sectors (Karanja et al., 2003). In 1999 there were about 1.3 million informal enterprises employing about 2.4 million people with $88 \%$ of the enterprises employed 1-2 people. The number of workers increased to 4.2 million by 2001 representing $43 \%$ of the working population of 10 million (Karaja et al., 2003). These figures demonstrate that informal and small businesses contribute substantially to job creation and often constitute the main source of income for some groups of societies around the world.

Workers in the small scale informal industries are affected by ergonomics-related injuries and illnesses that include musculoskeletal ailments such as chronic back-ache, neck and shoulder pain as well as eye strain and headaches (Hasle and Limborg 2006, Loewenson 1999, Rongo, 2005). The problem in Zimbabwe is that there are no known ergonomic guidelines for small scale enterprises since the sector operates mainly outside the legislative framework of the country (Chirisa 2009). A major challenge for the city authorities of Harare and Mutare is to come up with clear policies and actions aimed at supporting and nurturing the informal sector as well as improving health and safety in the sector. This study thus aims at assessing the awareness of ergonomics principles in the small-scale enterprises of Harare and Mutare. Harare is the capital city of Zimbabwe with a population of about 2 million people while Mutare is the fourth largest city located in the eastern part of the country on the border with Mozambique.

\section{2. $\quad$ Materials and methods}

The study was based on a survey of 600 workers involved in the small-scale sector as well as 200 from offices near the small scale industries and these were to be used as controls. The instrument that was employed in data collection was the questionnaire and it solicited information about complaints that were related to particular occupations. The respondents were interviewed about complaints related to particular jobs and whether they were aware of the four main areas of ergonomics which are human factors of engineering, work physiology, occupational biomechanics and anthropometry by answering specific questions that related to each of these areas. The questionnaire contained questions that pertained to common causes of accidents, work physiology (stress), occupational biomechanics (principles of lifting, principles of pushing and pulling) and the use of anthropometric data i.e. the mismatch between the worker and the workplace, equipment or machinery. The mean score was regarded as the level of awareness. The mean score obtained for the 600 workers was compared with the mean for the office workers, who served as controls. Health complaints related to ergonomics were assessed on the basis of individual responses. The complaints most reported by the workers in the small-scale industries were compared against those of the controls.

\section{Results and discussion}

Results of the survey show that there is a wide variety of jobs in the informal sectors of these two cities. Table 1 shows the distribution of workers involved in this sector based on the categories of informal sector identified by Niftrik et al. (2003). The sectors include retailing, manufacturing, repair, construction, service, care and transport. 
Table 1: Job types per sector of employment

\begin{tabular}{ll}
\hline Sector of employment & Type of Job \\
\hline Retail & Food vendor, salesperson, flourist, \\
Manufacturing & Carpenter, woodworker, furniture maker, clothing and textiles, home baker, \\
& graphic designer, basket-maker, weaver, meat processor, \\
Repair & Motor mechanic, bicycle repair, electrician, radio and TV repair, computer \\
& technician, shoe repair, metal recycler, tyre repair, \\
Construction & Builder, welder, painter, tiler \\
Service & Security officer, domestic worker, funeral businessman, day-care centre \\
& worker, gardener, secretary, tea provider \\
Care & Hairdresser, barber \\
Transport & Commuter omnibus driver, touts, breakdown service worker \\
\hline
\end{tabular}

\subsection{Occupational injuries, illnesses and hazards}

The occupational hazards associated with the small sectors of Harare and Mutare were in the form of injuries and illnesses. An occupational injury is an accidental injury that keeps a worker off from work for 24 hours or more (Niftrik et al. 2003). Table 2 shows the incidences of occupational injuries per sector of employment in Harare and Mutare. For the results an occupational injury incidence of 83 per 1000 workers was calculated. Male workers had 4.5 times higher risk of serious occupational injury than did women. The distribution of occupational injury was not homogeneous over the employment sectors. The more technical sectors also recorded the highest incidences of occupational injuries and these mainly involved broken bones (22\%) and fractures (16\%).

An occupational illness is any health problem related to or aggravated by work and forcing an employee to stop working. The self-reported illness incidence rate was 148 per 1000 workers and the highest rate was in the manufacturing sector at 316 per 1000 workers. The most common types of illnesses were musculoskeletal disorders and neck, back and upper and lower limb disorders and made up 36\% of all the self-reported illnesses caused by work. The high levels of stress, depression and headaches were attributed mainly to worries about incomes.

A total of 139 hazard inspections were undertaken with each hazard category comprising 10 occupational hazards. The number of times an occupational hazard was reported to be present was taken as a measure. The hazard ratio was the calculated by dividing this measure by the number of inspections completed per sector of employment. The results are shown in Table 3 which reveals that the repair sector is the highest risk employment sector associated with mechanical hazards such as electrical ones. Chemical hazards are most common in the field of hairdressers due to chemicals that are mostly applied without personal protective clothing such as gloves and are also stored in the open.

Table 2: Occupational injury incidence per sector of employment

\begin{tabular}{lrrrrrrrr}
\hline & Manufacturing & Care & Construction & Transport & Retail & Repair & Services & Total \\
\hline $\begin{array}{l}\text { People working in the } \\
\text { sector }\end{array}$ & 38 & 9 & 25 & 5 & 153 & 36 & 23 & 289 \\
$\begin{array}{l}\text { No. of occupational } \\
\text { injuries }\end{array}$ & 12 & 0 & 1 & 2 & 1 & 6 & 2 & 24 \\
$\begin{array}{l}\text { Occupational injuries } \\
\text { per 1000 people }\end{array}$ & 315.8 & 0 & 40 & 400 & 6.5 & 166.7 & 87.0 & 83.0 \\
\hline
\end{tabular}

A total of 21 mechanics were interviewed on healthy behaviour all of them male and aged between 20 and 40 years of age. It became clear that most men had some insight into the occupational hazards of their workplaces, but generally lacked thorough factual occupational health and safety knowledge. The respondents were able to mention certain safety related occupational health risks, but did not consider these hazards to be dangerous to their health (11 out of 21) or capable of causing disease (14 out of 21). An example is that of spray painters who considered their trade to be dangerous, but could not explain the health effects that were related to the job.

In the textile industry machines are usually placed in garages or living rooms and the activities include the production of school uniforms, dresses, curtains and bedding. There is a high risk of fire because the materials are easily ignitable and this problem is further exacerbated by the lack of fire -fighting equipment. The activities in the metal working industry expose workers to welding sparks, welding fire arc and fumes, extreme weather conditions and handling of hot material. The customers and passersby are also exposed to welding arc because these activities often take place outdoors. Personal protective clothing is rarely used due to financial constraints 
associated with these industries. In the informal sector, motor vehicle repairs are often undertaken on the street or in backyards. These industries are associated with a wide variety of risks that include poor lifting methods, the use of solvents such as benzene and thinners, lack of personal protection, inadequate sanitary and washing facilities and inadequate protection from fire.

The level of awareness regarding the major areas of ergonomics was found to be low in the small scale industries when compared against the office workers of Harare and Mutare (Table 3).

Table 3: Level of awareness (\%) concerning major areas of ergonomics among workers in Harare and Mutare

\begin{tabular}{lrrrr}
\hline Type of workers & $\begin{array}{r}\text { Human factors of } \\
\text { engineering } \\
\text { (Prevention of } \\
\text { accidents) }\end{array}$ & $\begin{array}{r}\text { Work physiology } \\
\text { (Prevention of } \\
\text { fatigue) }\end{array}$ & $\begin{array}{r}\text { Occupational biometrics } \\
\text { (Prevention of } \\
\text { musculoskeletal } \\
\text { disorders) }\end{array}$ & $\begin{array}{r}\text { anthropometric } \\
\text { data (postures } \\
\text { and work) }\end{array}$ \\
\hline Office workers & 83 & 51 & 63 & 61 \\
Motor mechanics & 47 & 21 & 31 & 17 \\
Metal workers & 56 & 20 & 27 & 16 \\
Builders & & & & 33 \\
Painters & 19 & 24 & 17 & 18 \\
Welders & 57 & 23 & 10 & 11 \\
Woodworkers & 48 & 16 & 13 & \\
\hline
\end{tabular}

Carpentry work involved manual planning, sawing, cutting, making holes, joinery, sanding, painting (polishing and vanishing), pulling or pushing finished furniture, strenuous lifting and cleaning the workshops. Woodworking machine operators operated woodworking machinery and the tasks done involved machine planning, sawing, cutting, mortising, making tendons, carving, drilling, joinery, servicing machinery, lifting and cleaning the workshops. Metal workers mostly made household utensils using new and scrap iron. Hard scrap metal was used to manufacture basins and buckets used in the construction industry. Some soldering was also done to join articles made out of tin metal scraps. The likely ergonomic problems associated with the jobs in this sector include excessive noise and the development of awkward body postures as well as stressors from heat, humidity and welding processes. In welding no benches are provided and kneeling and bending while welding in the direct sunlight were common place. Repetitive strain injuries are among metal workers as compared to the office workers and repetitive motion injuries were also common among spray painters and woodwork machine workers.

Table 4: Distribution of health complaints (\%) related to poor ergonomic practices

\begin{tabular}{lrrrrrrr}
\hline Health complaints & $\begin{array}{r}\text { Office } \\
\text { workers }\end{array}$ & $\begin{array}{r}\text { Motor } \\
\text { mechanics }\end{array}$ & $\begin{array}{r}\text { Metal } \\
\text { workers }\end{array}$ & builders & Painters & Welders & $\begin{array}{r}\text { Wood } \\
\text { workers }\end{array}$ \\
\hline Chronic back pain & 10 & 57 & 67 & 73 & 61 & 44 & 69 \\
Chronic neck pain & 6 & 66 & 77 & 84 & 66 & 76 & 22 \\
Chronic shoulder pain & - & 33 & 36 & 86 & 78 & 33 & 78 \\
Excessive heat & 18 & 44 & 51 & 23 & 54 & 54 & 66 \\
Excessive noise & 12 & 28 & 78 & 68 & 8 & 50 & 13 \\
Electric shock & 16 & 23 & 66 & 11 & 16 & 87 & 19 \\
Exposure to metal dust & 10 & 26 & 71 & 13 & 2 & 81 & 14 \\
Exposure to welding flame & 5 & 45 & 63 & 25 & 11 & 82 & 4 \\
Repetitive strain injuries & 42 & 68 & 76 & 74 & 49 & 71 & 56 \\
Repetitive motion injuries & - & 42 & 78 & 81 & 42 & 45 & 78 \\
No worktable or bench & - & 26 & 19 & 9 & 20 & 56 & 21 \\
Painting above shoulder level & - & 6 & 13 & 67 & 78 & 11 & 55 \\
Forging while sitting & - & 12 & 16 & 22 & 34 & 15 & 34 \\
\hline
\end{tabular}

According to Loewenson (1999) an occupational injury incidence of 208.5 per 1000 workers in the informal sector is much higher than that of the formal sector of Zimbabwe with more than 24 hours of lost time. In South Africa a study revealed that the occupational injury incidence was 83 per 1000 workers in the informal sector and this was 7.2 times higher than that in the formal sector (Niftrik et al 2003). The occupational health and safety situation in the informal sector is thus worrisome despite opportunities to improve the situation by implementing low cost and highly effective measures.

As in any other developing countries, the conditions under which most of the workers in the informal sector operate are precarious and unsafe. Some of the activities take place in households and the production of hazards directly affects living conditions. The risk of family members being exposed to workplace hazards during these 
residentially operated activities is relatively high, even though the family may not be engaged in actual production. The children involved in such activities are also at risk as they are undergoing developmental processes and growth and are therefore not as resilient to hazards as adults. The workshops are also mainly open shelters that lack sanitary facilities and potable water and suffer from inadequate refuse disposal methods. Waste disposal becomes a problem since the local authorities do not accept responsibility of collecting such waste production in residential zones unless the workshops are registered with them and a special fee is paid. It is because of this that hazardous waste is disposed in an improper manner and results in negative impacts on the environment.

Despite the fact that the informal economy contributes greatly to the economy of Zimbabwe it experiences constraints that inhibit the realisation of its full potential. The fact that most enterprises are family based and mainly operate outside the main institutional framework means that they are rarely supervised. Even those few that may be covered by law have low standards of health and safety and hardly meet the requirements for registration as places of work. The occupational accidents and disease are rarely reported and are never compensated. These industries are also not covered by the national social security and health insurance schemes and when old age or ill health affects their operators, many of the enterprises collapse. There is generally use of obsolete equipment with no protective clothing and thus multiple exposure to different ergonomic hazards occurs. The very small workshops suffer from poor hose keeping with tools and materials usually out of reach and working postures are affected resulting in strain. The carrying out of processes in the same place at the same time produces a lot of noise far beyond the recommended $85 \mathrm{Db}(\mathrm{A})$ for an hour working day. Welfare facilities and are generally lacking and sanitary facilities are-existent at roadside and open-air enterprises. A lack of fire-fighting equipment means that the number of fire-outbreaks is high as fires (usually for cooking) are lit near flammable materials. The workplaces were also found to be generally poorly lit and ventilated affecting the comfort of the worker.

\section{Conclusion and recommendations}

The level of awareness of ergonomics principles is low in the small scale informal sectors of Harare and Mutare. It was expected that builders, woodworkers and welders would have a higher level of ergonomic principles, but this was not the case. The informal workers are employed in a high-risk sector, but survey results indicated that improving their work environment is not one of their top priorities. The financial situation and the fact that occupational hazards and diseases are not always visible means that their limited resources are allocated to field other than occupational health and safety. Workers in the informal sector are not affected by the traditional employer-employee relationship as that obtains in the formal sector where the employee is obliged to care for the workers occupational health and safety needs.

In order to address occupational health and safety discrepancies in the informal sector there is need for change of mindset and this can be catalysed by the local authorities and other organizations. The local authorities can begin by ensuring basic occupational hygiene skills among the informal sector workers so that they may realize their economic potential and hence sustained businesses. This could be done by producing pamphlets and posters in English and the local languages as part of the awareness campaigns among the informal workers. An all-inclusive occupational injury and health insuarance scheme could be created in this sector to combat the impact of occupational accidents and diseases. A database that includes the latest information on better, safer and more productive tools could also be created for this sector.

Specific improvements also need to be undertaken to improve the working environment of the informal sector enterprises. These include the provision of racks for tools so that there is easy storage and retrieval. The materials not in immediate use need to be cleared to create room and improve the working space. Guard need to be fitted on machines as those used for grinding, trimming so as to avoid accidental start-up and also limiting unauthorized removal. The working environment could also be improved through concerted efforts by the enterprise associations in removing waste of any kind. The level of noise could also be improved through enclosure of the noisy enterprises. A major problem though could be providing sustainable improvement in ergonomics at the enterprises and multi-stakeholder participatory approach spearheaded by the city councils of Harare and Mutare and the National Social Security Authority of Zimbabwe (NSSA) would be essential in order to put the informal sector on a firmer footing in terms of health and safety.

\section{References}

Atambo, H. (1995). Work and hazards in Jua Kali industries in Kenya. African Newsletter on Occupational Health and Safety 5 (2): 32-34.

Chirisa, I. (2009). The geography of informal sector operations (ISO): A perspective of urban Zimbabwe. Journal of Geography and Regional Planning 2(4): 66-79 
Hasle, P. and Limborg, H.J. (2006). A review of the literature of preventive occupational health and safety activities in small scale enterprises, Industrial Health 44: 6-12. https://doi.org/10.2486/indhealth.44.6

Karanja, I.W.M., Muchiri, F.K., Muruka, A. (2003). Safety and Health in the informal economy. African Newsletter on Occupational Health and Safety pp. 4-6.

Loewenson, R.H. (2000). Health impact of occupational risks in the informal sector in Zimbabwe. International Journal of Occupational Environmental Health, 4(4): 264-274. https://doi.org/10.1179/oeh.1998.4.4.264

Loewenson, R. (1999) Assessment of health impact of occupational risks in Africa: current situations and methodological issues, Epidemiology 10: 632-639. https://doi.org/10.1097/00001648-199909000-00033

Miller, E. (2008). A study of ergonomic principles: Planning and survey. Nelson, New York.

Muchiri, F.K. (2003). Occupational Health and Development in Africa: Challenges and the way forward. African Newsletter on Occupational Health and Safety 13: 44-46.

Mukhopadhyan, P. (2008). Risk factors in brick manufacturing in India, Ergonomics Australia 22(1):16-25.

Nifrik, M., Boggaard, A., Lumens, M. (2003). Occupational health and safety in the urban economy in the Delft, South Africa. African Newsletter on Safety, Health and the Environment. 13: 13-15

Rogoeng, K.G. (2003) Safety and health in the informal sector and small-scale enterprises: The experience of Botswana. African Newsletter on Occupational Health and Safety, 13:13-15

Rongo, L. M.B. (2005) Are workers in Dar-es-Salaam aware of occupational ergonomics principles? African Newsletter on Occupational Health and Safety (15): 14-16.

Sett, M. and Sahu, S. (2010) Ergonomic evaluation of the tasks performed by female workers in the unorganized sectors of manual brick manufacturing units in India. Ergonomics South Africa 22(1):2-16

Tevera, D.S. and Chimhowu, A.O. (2000) Urban Growth, Poverty and Backyard Shanties in Harare. Geographical Journal of Zimbabwe, Number 31, Geographical Association of Zimbabwe, Harare 